Marquette University

e-Publications@Marquette

Philosophy Faculty Research and Publications

Philosophy, Department of

$11-28-2011$

\title{
Artificial Intelligence and Angelology
}

Howard P. Kainz

Marquette University, howard.kainz@marquette.edu

Accepted version. Crisis Magazine (November 28, 2011). Permalink. (C) 2011 Crisis Magazine. Used with permission. 


\section{Marquette University}

\section{e-Publications@Marquette}

\section{Philosophy Faculty Research and Publications/College of Arts and Sciences}

This paper is NOT THE PUBLISHED VERSION; but the author's final, peer-reviewed manuscript. The published version may be accessed by following the link in the citation below.

Crisis Magazine. Link. This article is (C) Crisis Magazine and permission has been granted for this version to appear in e-Publications@Marquette. Crisis Magazine does not grant permission for this article to be further copied/distributed or hosted elsewhere without the express permission from Crisis Magazine.

\section{Contents}

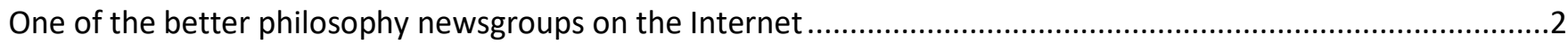

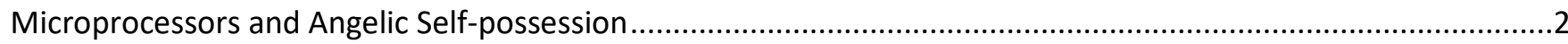

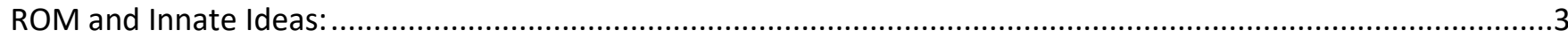

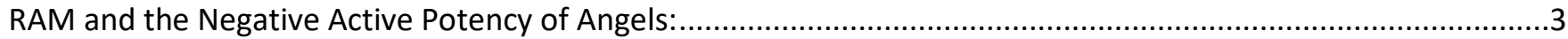

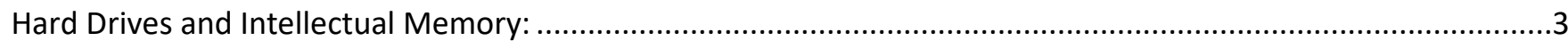

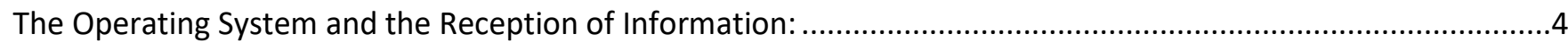

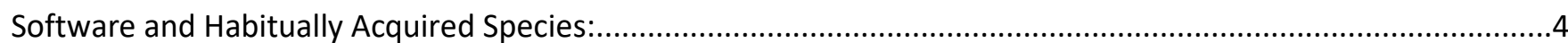

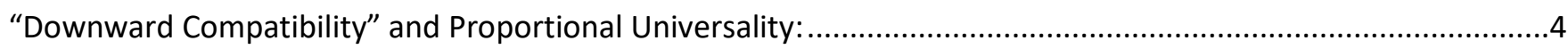

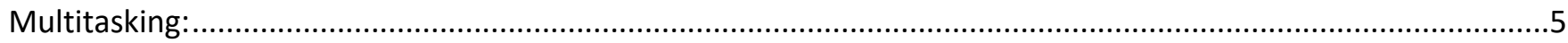

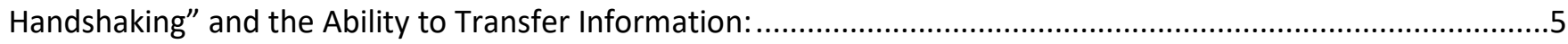

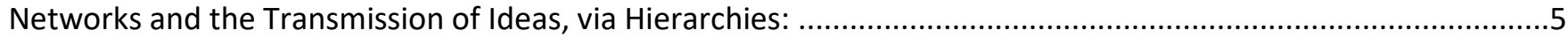

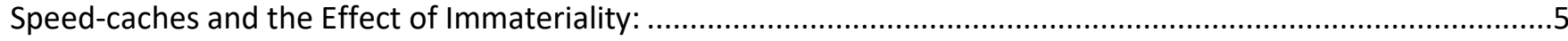

\section{Artificial Intelligence and Angelology}

\section{Howard Kainz}

Philosophy Department, Marquette University, Milwaukee, WI 
One of the better philosophy newsgroups on the Internet is entitled "comp.ai.philosophy." This group features constant variations on questions such as: How close can artificial intelligence (particularly computers) approximate to human consciousness? Is free will reducible to neurological mechanisms? and so forth. From my unscientific sampling, I would estimate that the clientele of this newsgroup is about evenly split between those who tend towards a reductive materialism, and those who maintain that consciousness or some element in human consciousness is not reducible to neural structures or functions. So the classical "Hobbes vs. Berkeley" debate continues on into the twenty-first century.

One of the problems facing those who theorize about the independence and irreducibility of consciousness is the fact that it is difficult to conceptualize the essence of consciousness, as distinct from the sensations, feelings, etc. that are often associated with consciousness. Here we are definitely getting into abstract metaphysics. Medieval philosophers such as Aquinas, Duns Scotus and Suarez faced up to this challenge with a little help from Christian revelation, by speculating about the characteristics and functions of angels or "separate substances," who would presumably exemplify consciousness in its "pure" state, without any distracting admixtures. In this article, I would like to take a look in particular at Aquinas' theory of separate substances. With this theory, we bypass the old question of the reducibility or irreducibility of consciousness to its material conditions, and we also find, in my opinion, some interesting analogies to contemporary computer technology. In some cases the analogies almost seem to throw light on Aquinas' speculations.

\section{Microprocessors and Angelic Self-possession: The microprocessors of today's} computers are integrated circuits which contain the CPU on a single chip or a few chips. The latest developments, with variable clock speeds now often exceeding $2.0 \mathrm{ghz}$, include Intel's $i 7$ and the AMD Phenom. The CPU chip is the heart of the computer; only memory and inputoutput devices have to be added. Fans, sometimes elaborate, are added on top of the fastest chips to cool them down, but in the chip itself there are no moving parts, no complex gaps between the movement being imparted and that which imparts the movement. So also, an angel, in Aquinas' formulation, is a simple, subsistent form, without any distinction between a material and an immaterial part, between matter and form. Since there is no such division, and thus no material impediment to self-possession, the angel possesses itself directly in an immaterial way, and possesses itself completely. But here is where the "middle term" enters: to possess anything in an immaterial way is to possess it cognitively, i.e., to know it. Thus the angel knows itself, its own essence, completely; and since will is proportioned to intellect, the angel's volition and "movement" is characterized by completely spontaneous selfdetermination on the basis of its knowledge. And just as increasing the clock-speed in certain types of processors narrows the gap between the issuance of a command and its implementation, so also the degree of immateriality of an angel decreases the gap between 
intention and accomplishment, principles and conclusions, causing the self-determination of the angel to approximate almost to instantaneity.

ROM and Innate Ideas: The chip storing the Read-Only Memory in a computer contains the immutable routines controlling input and output for the computer. It determines the basic functions of a computer, and cannot be modified in its essential functions by programs running in the computer. In a sense, it is the innate, predetermined program for the computer as a whole. So also, the angel is endowed from the time of its creation with an innate type of knowledge - the knowledge that results from possessing its own essence in an immaterial way, that is, cognitively, prior to acquiring any supervening intelligible species. It is capable of acquiring additional ideas, as we shall see below, but even prior to receiving additional species it knows itself completely and all other things in a partial manner, insofar as the perfections of these other things are contained in a unique way in the characteristics of its own essence.

RAM and the Negative Active Potency of Angels: The Random-Access Memory of a computer opens up the possibility of receiving an influx of data and images from programs and input devices; thus the maximum capacities of a computer can to a great extent be utilized only if maximal gigabytes of RAM, proportional to hardware and operating-system capabilities, have been installed in that computer. Angels, according to Aquinas, possess a negative or privative potency which is inversely proportional to their perfection. The higher angels have maximum act and minimum potentiality, while the inferior angels have proportionally "less act, more potency." The negative potency of all the angels is a side-effect of their finitude. The inferior angels, because of the greater relative deprivation of actuality in their form, need to be continually equalized with their superiors through the proportionally greater number of infused species they receive from their comrades and God Himself. Thus the lower angels have a greater capacity for receiving infusions of knowledge than the higher angels, and this capacity complements the greater power of the higher orders for giving such infusions.

Hard Drives and Intellectual Memory: A distinction is made in contemporary computers between "main memory" or storage capacity, and the volatile memory in RAM. When "memory" is spoken of without further qualification with reference to computers, RAM is usually meant. When the "memory" of intellectual beings is referred to without further qualification, something like "storage capacity" is usually meant. Among intellectual beings, humans have both sense memory and intellectual memory. Using a little literary/philosophical license, we might say that sense memory for human beings is analogous to external storage devices such as CDs, DVDs or flash drives that can provide ad hoc input to a computer, while intellectual memory is analogous to the more permanent storage provided by hard disks or the "cloud" of Internet storage of data and apps. Whatever the merits of this analogy, angels, according to Aquinas, being purely spiritual creatures, have only intellectual memory, not sense memory. For them, there is no such thing as externally-received input in the strict 
sense. A comparison with Leibniz's monads, which mirror all things in an intrinsic fashion, is probably in order here. In other words, images of all things, including sense objects, are stored in an angel's intellectual memory; and these images can be accessed and applied whenever needed.

The Operating System and the Reception of Information: Granted that RAM gives a computer the capacity to receive information, how does the data actually come to be accessed? The answer to this question in the case of computers is obviously the operating system; a computer must have an operating system such as Windows 7, Mac OSX, or Linux, to begin receiving data and commands. Human beings, because of their corporeality and discursive type of rationality, must process information sequentially with what Aristotle called the "possible intellect." But according to Aquinas, angels being completely incorporeal do not have a "possible intellect" in the strict sense, although we could say that the angels of the lower orders have a "quasi-possible" intellect insofar as they are in potency to receiving intensifications of illuminations from the higher orders. But they do not need a possible intellect to begin processinginformation. Like a computer shipped with an operating system fully installed, angels are fully equipped at their creation with innate and habitual intelligible species.

Software and Habitually Acquired Species: In a computer, information, techniques and procedures not contained in ROM and not included with the operating system, are supplied by supplementary software. According to Aquinas, angels continually and unendingly receive habitual impressed species directly from God as a supplement to the connatural knowledge which they have through their own essence. Even at creation, before they were tested for fidelity, these species provided them with their natural knowledge of God; the species likewise endow them with a knowledge of all beings other than God. There are some limitations to their knowledge of other intellective beings, however. Something like a "right to privacy" is operative amid the angelic hierarchies, since angels cannot have access to the thoughts of other angels, unless the other angels explicitly will that they have such access. These restrictions apply also to angelic interrelationships with human beings: they cannot have direct access to human thoughts, although they can gain some knowledge of the thoughts of human beings indirectly, from observation of their dispositions, movements and appetites.

"Downward Compatibility" and Proportional Universality: Later versions of software are usually able to do all the things that earlier versions of the same software could do. So also, the higher angels contain more universal and fewer species than the lower; these species contain in a simpler way everything that is contained in the species of subordinate orders, thus increasing the scope of comprehension and the parameters of influence of the higher orders. Thus the superior angels might be compared to the manager who knows how to do everything that his/her subordinates can do, but specializes just in a supervisory function. 
Multitasking: Contemporary operating systems when installed in a sufficiently advanced microprocessor offer the capability of "multithreading" (32-bit or 64-bit on most home computers) whereby multiple tasks can be carried out simultaneously - for example, simultaneous printing, copying to disk, and search-and-replace operations. If I am presently working on a particular task, this is designated the "foreground" task, while the other operations are carried out in the "background." In like manner, angels are characterized as having the ability to know and do multiple things at once. In one simple act, they know all the variety of particular things, although they can bring this or that object into the "foreground" by turning their attention to it. They are also continually combining the knowledge of things as they exist in God (cognitio matutina) with the knowledge of things according to their own proper existence (cognitio vespertina). And an angel also has the ability to engage in "oblique contemplation" (simultaneous combination of action and contemplation).

Handshaking" and the Ability to Transfer Information: Individual computers or local network nodes can come into contact via modems with their counterparts through a process called "handshaking." Ethernet cards have a similar function. Signals are sent out, for example, from a browser, and coordinated, and as a result commands can be processed, binary and text files can be transferred from a server. According to the Thomistic theory of separate substances, angels cannot receive new intellectual species from other angels, but they can receive an intensification of illumination of the species they already possess by coming into intuitive contact with other angels; an angel of a higher order merely wills to communicate something and it is instantaneously transmitted.

Networks and the Transmission of Ideas, via Hierarchies: In networks, signals are sent from major servers and their "mirrors," sometimes through a chain of many intermediate servers (as in Internet transmissions), until they reach an end "user." In the angelic hierarchies, the gifts of grace among angels must always be proportional to the gifts of nature (unlike the case with humans, where, for example, someone with little native intelligence could be much more generously endowed with grace than a highly gifted individual). And so, angelic communications always take place from the naturally superior to the naturally inferior. But, as was mentioned above, the communication does not involve the transmission of new species, but only an intensification of illumination. What this means is that a superior angel can cause in an inferior a heightened perception of species the latter already possesses, or offer different insights or perspectives on the knowledge the latter possesses; or possibly put his own higher species into terms more comprehensible by the other angel, like a teacher explaining advanced concepts in simpler terms to a student.

Speed-caches and the Effect of Immateriality: Speed caches in computers consist of high-speed memory within the main processor. They help to increase computing speed by providing a route for signals to avoid getting slowed down by operations in the hard disk, 
which is mechanical and relatively slow, or by calls for data from the RAM memory, which is faster, but slower than the cache in the CPU. Bits of programs or data can be stored in the speed cache to facilitate almost instantaneous access. An angel, on the other hand, completely avoids problems of slow transmission; it simply has no matter to slow it down. Thus, for all practical purposes, and from our corporeal vantage point, all angelic operations and comprehensions are instantaneous.

It should be mentioned, however, that there was considerable disagreement among medieval and patristic authors concerning the "immateriality" of angels. Augustine and Origen had speculated about the possibility of angelic bodies being composed of matter, albeit a more "subtle" matter. Duns Scotus gave lip-service to the received doctrine of angelic incorporeality, but challenged his readers' imagination by theorizing that angels must have some kind of "incorporeal" matter (maybe something like the "dark matter" that physicists talk about?); and, consistently with this theory, Duns Scotus thought that angels must reason discursively in some fashion. If there were any kind of matter in angels - subtle or "incorporeal" - the leap from completely immaterial beings to partly material beings would be less formidable, and the analogy between angelic spontaneous instananeity and the linear, sequential operations of computers would be even closer.

Howard Kainz is professor emeritus at Marquette University. He is the author of several books, including Natural Law: an Introduction and Reexamination (2004), The Philosophy of Human Nature (2008), and The Existence of God and the Faith-Instinct (2010). 